\title{
E-PÍSTOLAS: \\ AS VIDEOPOESIAS DE MATILDE CAMPILHO E A RELAÇÃO LITERÁRIA ENTRE BRASIL E PORTUGAL
}

\author{
Tiago Radatz Kickhöfel ${ }^{96}$ \\ Claudia Lorena Fonseca ${ }^{97}$
}

RESUMO: Este texto apresenta um percurso de articulações teóricas e críticas possíveis para a leitura de um projeto literário hipermidiático e do seu reflexo em um sistema cultural mais amplo. Trata-se do projeto videopoético da escritora Matilde Campilho e seus desdobramentos na perplexa relação literária entre Brasil e Portugal. Eis que se divide em duas partes, na primeira justifica sua posição critica e localiza a poeta e sua produção no estudo, bem como verifica motivações históricas motrizes de tais ruídos no diálogo literário luso-brasileiro; a segunda parte é dedicada à análise formal da videopoesia e suas imbricações no corpus poético selecionado, o videopoema Fevereiro. O objetivo desta análise é, portanto, entender essa problemática cultural e o modo pelo qual a autora a contornou, isto é, a dupla perspectiva de alteridade que cumpre em seu projeto-processo literário hipermídia.

Palavras-chave: identidade, hibridação cultural, videopoesia

RESUMEN: Este artículo presenta un curso de articulaciones teóricas y críticas posibles a la lectura de un proyecto literario hipermedia y su reflejo en un sistema cultural más amplio. Este es el proyecto videopoético de la escritora Matilde Campilho y sus desarrollos en la perpleja relación literaria entre Brasil y Portugal. He aquí se divide en dos partes, la primera, justifica su posición crítica y presenta la poeta y su producción en el estudio y verifica las razones históricas que causaron tales ruidos en el diálogo literario luso-brasileño; la segunda parte está dedicada al análisis formal de la videopoesía y su superposición en el corpus poético seleccionado, el videopoema Fevereiro. Por tanto, el objetivo de este análisis es iluminar este

\footnotetext{
${ }^{96}$ Videomaker, aluno no curso de licenciatura em Letras pela Universidade Federal de Pelotas, pesquisa e produz artes hibridas entre palavra e imagem; bolsista PBIP UFPel - e-mail: tiagadatz@gmail.com.

97 Doutora em Literatura Comparada, Professora Adjunta do Centro de Letras e Comunicação da Universidade Federal de Pelotas - UFPel - e-mail: fonseca.claudialorena@gmail.com.
} 
tema y ver cómo la autora se lo pasó a través de la doble perspectiva de la alteridad que se cumple en su proyecto-proceso literario hipermedia.

Palabras clave: identidad, hibridación cultural, videopoesía

I

"A essa hora na Terra é metade

Carnaval, metade conspiração"

Este artigo muito resulta da questão que em princípio parecia fundamental à conclusão da pesquisa: a partir de uma literatura culturalmente ambivalente, qual perspectiva de abordagem deve-se tomar para compreendê-la em essência? A resposta, como se verá adiante, não pode ser polarizada, pois acaba diluída junto às fronteiras que a hibridez motriz dessa literatura dissolve. $O$ fenômeno da multiculturalização na literatura não é recente, nem o são os estudos que tratam sobre o tema, havendo significativos avanços nas áreas dos estudos culturais e da literatura comparada que propõem localizações intermediárias, migrantes e despolarizadas, permitindo uma inserção crítica que ultrapassa o "reflexo de traços culturais ou étnicos pré-estabelecidos, inscritos na lápide fixa da tradição" (BHABHA, 1998, p. 20). Estas localizações críticas erradias, fluídas e intersticiais possibilitam a análise de projetos literários cuja hibridação (fundição, em alguns casos) de culturas distintas ultrapassa o nível da influência e passa a ser o da experiência concreta e intrínseca à criação literária, pois permitem a transparência do cimento natural que une culturas em tais casos, que é a identidade própria do processo, essência e produto dessa criação, sem o risco do seu esfarelamento, potencialmente causado por uma localização crítica delimitada.

Transferindo a problemática à poética em estudo - a produção videótica de Matilde Campilho - a questão fica mais evidente: por ter sido criada a partir da experiência real da poeta lisboeta no Brasil e das imbricações deste deslocamento, ao focar a pesquisa unicamente nas influências culturais brasileiras em tal projeto poderão ser despercebidos elementos semânticos da cultura portuguesa que são ressignificados pela experiência com a local; do mesmo modo, lançar-se aos estudos da relação literária portuguesa, por exemplo, com a historicamente pautada epistolografia (estudada neste artigo) levará a uma leitura insuficiente, não sendo considerada a motivação transatlântica da "eu-lírica-remetente". O 
imbróglio na localização torna-se ainda mais complexo quando, além da poeta ser este sujeito migrante, de dupla inscrição cultural, sua manifestação literária se concretiza na internet, caso de seus videopoemas, uma vez que neste espaço virtual não há um território delimitado.

Em uma entrevista dada pela poeta ao caderno de cultura do site $\mathrm{O}$ Globo $^{98}$ a jornalista apresenta a escritora como "muito brasileira em Portugal e muito portuguesa no Brasil”, sugerindo um imanente deslocamento da poeta dita "nômade", ignorando os processos de adaptação e pertencimento que regem sua produção. $\mathrm{O}$ que fez perceber que não importava tanto à pesquisa uma localização crítica precisa e/ou delimitada, mas esta deveria fluir tal qual a poeta, tal qual sua poesia, seguindo seus fluxos e influxos culturais. Ou seja, para analisar uma produção poética cuja essência é o deslocamento de sua criadora e o duplo papel de alteridade que cumpre neste processo, também a análise deve ser dinamizada por este fenômeno. Assim, passamos a discutir não só a produção poética da autora, mas seus processos de criação, intrinsecamente ligados à experiência da poeta em trânsito, visto que parte dele e do que ele provoca a matéria e a forma de sua poesia, acabando por refletir também no sistema literário onde se insere esse movimento.

Matilde Campilho nasceu em Lisboa e, entre outras andanças, morou no Brasil entre 2010 e 2013, onde começou sua carreira literária. Enquanto recebia a cidade, teve contato com o movimento literário do Rio de Janeiro, dialogando com poetas como Chacal e Carlito Azevedo, publicou o primeiro poema, Fur, no suplemento literário da Folha de S.Paulo e, ao passo da sua poesia ganhando formas, os diálogos com a cultura e a produção poética brasileira cada vez mais marcados. O plural em formas vem das manifestações imagéticas de sua literatura; desde o primeiro ano no Rio a poeta registrou instantes em vídeo e os ressignificou com poesia, publicando em seu canal no site Youtube uma série de videopoemas durante esse período. Também em imagens transcriou seu poema Honey Boo, em parceria com o artista visual Odyr Bernardi, na forma de quadrinhos, publicados periodicamente no blog do projeto ${ }^{99}$. É em 2014 que Matilde publica seu primeiro livro, Jóquei, em Portugal (Ed. Tinta-daChina), seguida pela edição brasileira (Ed. 34), em 2015. Sobre a hibridação

\footnotetext{
98 "Matilde Campilho, uma poeta nômade", por Mariana Filgueiras. Disponivel em <http://oglobo.globo.com/cultura/livros/matilde-campilho-uma-poeta-nomade-12953888>. Publicado em 21/08/2014. Acesso em 28/03/2015.

${ }^{99}<$ https://honeyboocomics.wordpress.com/>
} 
cultural observada em sua arte, esta parte dos processos de reconhecimento e assimilação da poeta no novo espaço em diálogo com suas experiências subjetivas, manifestando na linguagem esta relação; dai versos como "O brasileiro acha que o amor é importante porra, eu cá não acho nada” onde podemos notar o encontro da cultura popular brasileira (uma pichação que figura em muros de todo o país), antecedendo uma construção sintática recorrente no português de Portugal. Essas ocorrências estão presentes em boa parte de sua poética e, também ao lado de gerúndios e plural em "gentes", lemos inscrições em outras línguas e referências a outros lugares e culturas, e, neste interstício onde a erudição ganha o fermento do estilo, parece incerto, ao menos no que tange à sua literatura, dizer-lhe portuguesa.

Atenta ao que a circula e com cuidados fraternos com essa matéria, a poeta conclui, por exemplo, ao analisar a estrutura do DNA em uma de suas poesias, que "a raça humana é toda brilho", firmando seu lugar no sistema literário contemporâneo, seguindo a tendência semântica observada por Cyntrão neste sistema (2008, p. 86): “a despeito de toda a fragmentação do sujeito na pós-modernidade, há uma tentativa de recuperação dessa inteireza perdida", metaforicamente recuperada no exemplo mencionado, que parte da menor unidade identitária do ser, o ácido desoxirribonucleico, até a sua macroestrutura, a raça humana, que é toda brilho. Aos leitores desatentos, o bucolismo e a busca pela simplicidade de alguns versos da poeta podem parecer esteticamente deslocados, reduzindo-os ao espaço de poetas anacrônicos que por vezes ressurgem dos morros da Arcádia. No entanto, esta inclinação ao natural tem tanto a ver com essa reconstituição do sujeito pós-moderno em descanso da ressaca ideológica do último século, como com a particularização do fazer poético, também observado por Cyntrão como sintomático da produção lírica contemporânea.

É devido a este hibridismo que Matilde ultrapassa um trauma histórico entre as literaturas brasileira e portuguesa, manifesto no cânone literário e suas instituições. No panorama contemporâneo desta relação o quadro não é diferente, em uma crítica para o caderno de cultura do jornal Público ${ }^{100}$, de Portugal, a crítica Isabel Lucas percebe o antagonismo nos diálogos literários lusotupiniquins:

\footnotetext{
100 Portugal e Brasil: orgulho e preconceito entre duas literaturas. Isabel Lucas. Caderno Cultura Ípsilon, do jornal Público, Portugal. Disponivel em <http://www.publico.pt/culturaipsilon/noticia/portugal-e-brasil-orgulho-e-preconceito-entreduas-literaturas-1690391>. Publicado em mar. 2015. Acesso em 16 jun. 2015.
} 
O convivio entre as literaturas portuguesa e brasileira não é pacífico. Há fascínio e desconhecimento, folclore e preconceito, arrogância e admiração. Nos últimos anos, portugueses passam e fixam-se em território brasileiro e transportam essa paisagem para a sua escrita. Acontece com brasileiros, mas menos. Como se dá o contágio? Quem escreve e quem lê traça um retrato onde a língua é elo e barreira, mas sempre vista como impermeáveis acordos diplomáticos (LUCAS, 2015, s/p.).

Estas barreiras são expostas de diferentes modos, com maiores exemplos vistos no sistema literário português, evidenciados pela parca circulação da literatura brasileira, bem como seu ensino limitado nos cursos de Letras e intercâmbios quase unilaterais de escritores; também na própria língua, onde residiria a aproximação essencial para o diálogo, se percebem ruidosos acordos, caso de escritores brasileiros a rigor publicados em Portugal sob adaptação gramatical das editoras, ou, invertendo o fluxo, de escritores consagrados, como José Saramago, que proíbem expressamente em seus livros adequação ortográfica nos países falantes de língua portuguesa. Mesmo o projeto em estudo, constructo de um "português carioca-lisboeta”, teve que legitimar a necessidade semântica de hibridação linguística para ser publicado sem alterações.

Para entender o conflito é necessário atentar aos processos históricoculturais que o motivaram. Nesse sentido, dois momentos de reconstruções identitárias foram decisivos na formação de tal ranço reflexo na literatura: no período pós-colonial, a libertação linguística brasileira, que atiçou o forte "instinto de nacionalidade" na cultura local, gerando uma espécie de ressentimento na ex-matriz; e, na modernidade, o ideal difuso de lusofonia, imaginado como "um cimento natural entre os povos falantes de língua portuguesa" (LOURENÇO, 2001, p. 191), proposto de modo a resgatar relações esfaceladas após os movimentos de independência.

Amplos estudos abordam a questão da transição linguística no português brasileiro no século XIX, como as análises precisas de Tarallo (1989; 1993), e também sobre suas reminiscências na língua corrente (BAGNO, 2001; PERINI, 1995), que apontam tal movimento de reinvenção da língua como um catalisador do desejo de uma identidade própria da nação, ao menos de modo análogo, no período de ressaca pósindependência; tomando de empréstimo contrastante, "Minha pátria é 
minha lingua". Um exemplo deste fenômeno que deixa muito clara a motivação social de reestruturação linguística pode ser percebido no gráfico elaborado por Tarallo (1993), que mostra a inversão do uso pronominal em sujeitos e objetos diretos no português do Brasil entre 1725 e 1982:

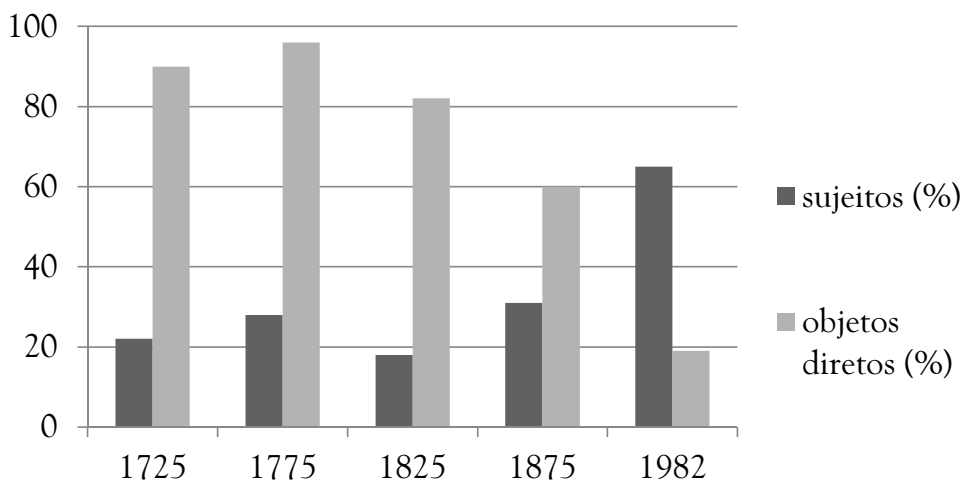

Este exemplo mostra que a partir da independência (1822), um movimento linguístico passou a centralizar o sujeito nos enunciados, gerando "contextos que exibem um referente sintaticamente e discursivamente acessivel" (KATO et al, 2006, p. 417), ou em termos sociais, um sujeito ativo, consciente de seu papel e identidade.

Também na literatura o desejo de independência cultural foi marcado, inicialmente forjado sob as teses do romantismo de literatura nacional e sentido de nação, explicitados por Machado de Assis em seu ensaio "Instinto de Nacionalidade" (1873), onde o escritor afirma que

Quem examina a atual literatura brasileira reconhece-lhe logo, como primeiro traço, certo instinto de nacionalidade [...] todas as formas literárias do pensamento buscam vestirse com as cores do país, e não há negar que semelhante preocupação é sintoma de vitalidade e abono de futuro (ASSIS, 1873, s/p.).

Ideal retomado com outras configurações no período modernista, traduzido no conceito de antropofagia proposto em seus manifestos para 
"deglutir" o legado cultural europeu e "digeri-lo" sob a forma de uma arte tipicamente brasileira, através de uma "lingua literária não-catequizada".

O professor e filósofo português Eduardo Lourenço percebe que este desejo de independência cultural produziu em seu país uma espécie de "ressentimento de imaginários pais mal-amados ou ignorados, por momentos cedendo à tentação de nos enervar com a desatenção brasileira a nosso respeito." (LOURENÇO, 2001, p. 141). Sendo possivelmente esta desilusão o estopim dos ruidosos diálogos culturais entre Brasil e Portugal.

Para contornar essa problemática, surge de modo difuso e impreciso o ideal de lusofonia, aspirando uma comunhão entre os países falantes de LP. Entretanto, a falta de empatia em sua proposição o torna irrelevante para os povos além de Portugal, que não percebem vantagens no resgate histórico forçado por este ideal, primeiro porque, como lembra Margarido (2000, p. 6), "a invenção da lusofonia foi feita através de uma espécie de amnésia coletiva em relação à violência que foi exercida sobre aqueles que, hoje, falam português", e, segundo, porque parte de uma suposta centralidade portuguesa no processo, onde "'Outro' e 'Eu' deveriam ser convocados numa perspectiva de alteridade, da diferença antes que da subalternização" (MUNIZ, 2009, p. 1).

Portanto, o que se percebe atualmente neste panorama são resquícios de traumas históricos e políticos oriundos dos movimentos de independência cultural. No Brasil essa ruptura não é mais tão visivel como o é em Portugal, mas a exemplo de Campilho, que engendrou uma literatura híbrida e livremente transitória, contornando obstáculos linguísticos e culturais ao impossibilitar a definição de "onde começa Portugal e onde termina o Brasil, e vice-versa" ${ }^{101}$, surpreende também o sistema literário brasileiro - o que confirmam os dados da FLIP 2015 (Festa Literária Internacional de Paraty - maior evento literário do Brasil), onde o seu livro de estreia figurou no topo dos mais vendidos, feito inédito em vários níveis (primeiro livro, de poesias, escritora mulher, "portuguesa").

"O amor é um animal tão mutante, com tantas divisões possiveis"

101 Como escreve David Pimenta em critica sobre o Jóquei para o blog Deus me livro. Disponivel em: <http://deusmelivro.com/critica/joquei-matilde-campilho-21-7-2015/>. 
Apresentado este quadro e localizando a escritora em seu contexto, passamos a analisar suas primeiras manifestações literárias, isto é, suas videopoesias, que além de transparecerem o hibridismo cultural discutido até aqui, apresentam atualizações formais na sua construção que contribuem para a discussão alçada. Essa produção está publicada no canal da autora no Youtube e evidencia nos registros os seus processos subjetivos de assimilação e adaptação. Como lembra a poeta, na entrevista já citada ao Jornal Público: "A cidade estava a mudar muito, e eu também. Ao mesmo tempo eu era estrangeira, então estava permeável a tudo, receptiva a muitas coisas. À paisagem, à mentalidade, aos valores, e até à língua”. Nesta permeabilidade estética, as mais imediatas absorções do novo espaço, da cidade ainda crua de rotinas à estrangeira, foram expostas por Matilde na forma de registros videóticos de momentos ditos comuns; instantes rotineiros, mas de leitura que foge à simples observação da paisagem visual e propõe algo de contemplação. Imagens escolhidas entre tantas dos dias, onde o espaço para as palavras é limitado, ou mesmo desnecessário. Eis que os três primeiros vídeos de Matilde no Youtube são de olhares da poeta em trânsito sobre a cidade, ao som incidental de músicas brasileiras, sem a matriz verbal-poética. $O$ que retoma a discussão sobre a necessidade ou não de linguagem verbal para a construção da videopoesia e se estas primeiras experimentações/experiências de Matilde já poderiam ser consideradas como tal.

Carlos Monção Amâncio (2014), pesquisador da poesia digital, em seu artigo dedicado à problemática, traz um significativo panorama sobre as definições de videopoesia e suas unidades a fim de propor um conceito que prescinda do uso da matriz verbal na sua composição, alegando que a imagem tensionada por um ritmo poético de edição (muito próximo da montagem orgânica dos cineastas russos da década de 30), seria suficiente para criar "o núcleo semântico, citado por Charaudeau (2007), necessário para que se efetue a materialização sociodiscursiva do imaginário, que, nesse caso, é uma videopoesia" (AMÂNCIO, 2014, p. 216). Porém, justamente por essa aproximação das teorias de montagem cinematográfica, que buscaram caminhos análogos aos percursos psíquicos do espectador através da edição - para Eisenstein (1976), com o objetivo de atingir o Patético (o sair de si mesmo, a condição de extremo encantamento e êxtase atingida pela organização formal das unidades do filme) - estas manifestações videográficas não-verbais podem ser localizadas sem imbróglios teóricos no âmbito do filme-ensaio, que além de não construir- 
se a partir da linguagem verbal, possui a subjetividade que o gênero ensaio, em sua essência, expõe; assim, podemos ler os primeiros vídeos da poeta no Brasil como ensaios sobre situações e lugares, cujo registro parte da subjetividade, mais, da presença da autora significando a experiência, ou seja, uma estrangeira em contato e adaptação à nova cultura. Isso, somado à ideia de epistolografia digital a qual este artigo busca invocar para a leitura da obra audiovisual da poeta, estas primeiras produções de Campilho funcionam, metaforicamente, como uma espécie de postais audiovisuais. Sobre a problemática, concluo então que, para a formalização da videopoesia, a linguagem verbal faz-se necessária, sendo a matriz que difere esta de outras formas de videoarte.

A inclusão da matriz verbal se dará no seguinte vídeo publicado no canal, "dia dez" (3min59seg, publicado em 11/9/2012), sendo a primeira de suas videopoesias a circular na internet. $\mathrm{O}$ corpus poético especifico desta pesquisa é o sexto e (por enquanto) último videopoema da autora, Fevereiro (5min24seg, publicado em 11/3/2014), escolhido por já transparecer familiaridade com o lugar que provoca a sua poesia e, pela data de publicação, o fato de a poeta não mais morar lá, simbolizando certo fechamento de ciclo.

Para analisar a forma videopoética, partimos, portanto, das teorias sobre as matrizes da linguagem e do pensamento de Lúcia Santaella (2001), principalmente por contornar as infrutiferas discussões sobre localização de obras nos campos das artes, isto é, pertencimento da videopoesia à arte literária ou visual. Assim, videopoesia pode ser vista amplamente como um produto da linguagem (considerando sua multiplicidade), que, segundo a teórica, se manifesta em combinações ou hibridações entre três matrizes visual, sonora e verbal (poética).

Desse modo, para adentrar a crítica com um certo formalismo e apresentar a obra, percebe-se na matriz visual de Fevereiro dois campos semânticos: a) praia carioca - imagens de palmeiras, areia, água de coco, morro Dois Irmãos, orla de Copacabana e morro da Rocinha; b) viagem imagem subjetiva de alguém dentro de um carro em trânsito na autoestrada, cordas e mastros de embarcações, traço de avião no céu. Apenas nesta observação já podemos verificar a ideia de deslocamento da poeta, o que também evoca sua poesia, e uma possivel localização dos seus agentes líricos: leitor-destinatário no Rio de Janeiro, "eu-lírica-remetente" em outro lugar, possivelmente Lisboa. Na matriz sonora-musical escutamos uma música com base em piano, em andamento andante, ritmo progressivo 
e tom melancólico. Na matriz verbal-poética é onde escutamos, à voz da eulírica, saudades e pensamentos divididos com um interlocutor não identificado, numa espécie de leitura epistolar.

Especificando cada uma das matrizes e descrevendo-as sobre o corpus em questão, observa-se que tais matrizes se constituem da seguinte forma:

a) Matriz sonora: para Santaella, é própria dessa matriz a construção sintática (combinação dos elementos a fim de formar unidades mais complexas) e a temporalidade. Em Fevereiro esta matriz corresponde ao elemento musical do videopoema, assim, sua sintaxe é a da convenção musical, acima descrita. A melodia melancólica da obra projeta seu efeito às outras matrizes, naturalmente, efeito associativo definido por Michel Chion (1995), compositor e pesquisador do som no cinema, como "valor agregado".

b) Matriz visual: formaliza-se na dimensão espacial (imagens em movimento são, portanto, hibridação entre a matriz visual e sonora, onde se realiza a dimensão temporal). Na tríade classificatória desta matriz, as imagens de Fevereiro podem ser consideradas "formas figurativas" de "índices genuínos", pois os vídeos apresentados têm conexões existenciais com seus objetos. No entanto, dessa associação semiótica não se deve ler o significado como produto direto, isto é, ele não é gerado apenas por seu correspondente significante (o objeto), mas pela relação do signo com o sistema cultural mais amplo. Exemplos claros podem ser observados em Fevereiro: a primeira informação visual que se lê no videopoema é a imagem de uma palmeira, e sua correspondência transcende o objeto e paira no sistema literário brasileiro, onde é símbolo de brasilidade desde o período romântico, graças aos célebres versos de Gonçalves Dias, em sua Canção do Exilio, ainda pensando nessa relação intersemiótica, fica também evidente o deslocamento de Matilde Campilho em relação ao lugar que evoca em imagens, o Rio de Janeiro, $\mathrm{O}$ Brasil, a terra das palmeiras. $\mathrm{O}$ mesmo poderia ser dito em relação à segunda informação visual, já que as cordas e mastros da embarcação aparecem e se repetem quatro vezes ao longo da videopoesia, podendo ser relacionadas tanto com o campo semântico de distanciamento, como ainda evocar algo mais específico, como o florescimento da epistolografia no quadro histórico das grandes navegações portuguesas do século XVI. 


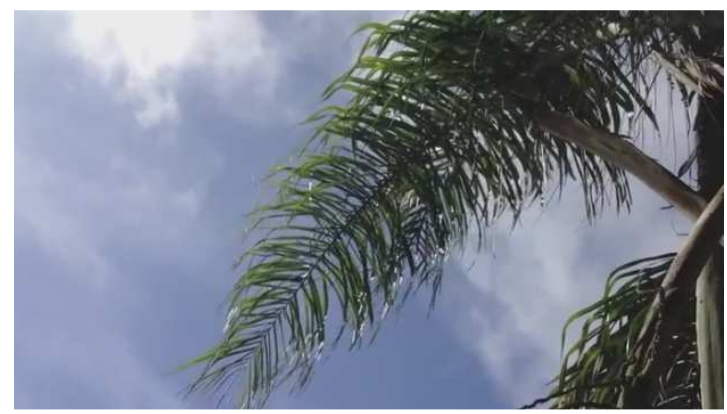

Figura 1: screenshot de "Fevereiro", M. Campilho: 0'1"

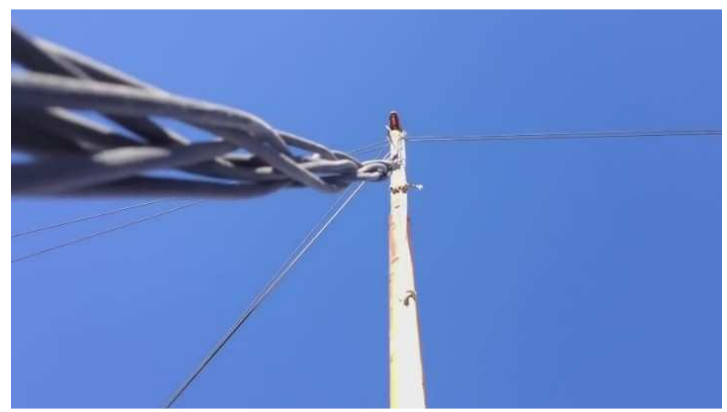

Figura 2: screenshot de "Fevereiro", M. Campilho: 0'13"

c) Matriz verbal: podendo ser materializada sonora ou graficamente (em Fevereiro, é texto sonoro), tem como propriedade o discurso (no caso das videopoesias, o discurso poético), se organiza na sequencialidade temporal e espacial e na convenção do signo, cuja categoria universal em Fevereiro é a "secundidade", isto é, a narração, que traduz ações e eventos em um ato narrativo e, por isso, comunicativo. Na obra em questão, graças às pistas do discurso epistolar ali presentes, como a interpelação de um sujeito leitor, as características semânticas dessa matriz podem ser aproximadas, com ressalvas à atualização do estilo, à epistolografia portuguesa de caráter literário, também porque a partir dessa consideração foi possivel compreender a videopoesia em um contexto mais amplo e polissêmico. Já em Cartas Portuguesas, de 1669, de autoria designada à Mariana Alcoforado, se observa a matéria de Fevereiro: a saudade e o amor. Esta observação encontra suporte no momento político e social de Portugal do século XVI, o período das navegações e ampliação territorial, onde os 
homens partiam em longas viagens e deixavam as mulheres com suas penas, em termo ambivalente. É neste contexto que Prado (2010, p. s/n) percebe que as "Cartas Portuguesas constituem-se, dentro da literatura lusa, como um importante elemento formador do imaginário amoroso português de voz feminina”. Ressurgindo aqui como uma reminiscência ou alusão deste estilo. No entanto, a virtualidade poética de Campilho ao mesmo tempo a afasta consideravelmente do campo já tênue da literatura epistolar e problematiza-o ainda mais ao formalizá-la em imagens em movimento e som publicadas na internet, pois, por um lado, o caráter de segredo, um dos atributos que determinam o estatuto ficcional ou literário da escrita epistolar, de acordo com Rocha (1965, p. 14), é corrompido, e, por outro, a virtualidade proximal proporcionada pela rede globalizada poderia, no mínimo, diluir o conteúdo da e-pístola nesta ilusão.

É importante, neste contexto, observar o fenômeno da realização literária na internet e localizar a produção da poeta neste quadro. Fajardo (2011) percebe três ocorrências desta manifestação literária na rede: primeiro, uma "memória fugaz", global, imediata, ubíqua, cuja transcendência "está marcada pelo que podem perdurar os textos na rede"; por consequência, o segundo ponto é a importância do momento presente nesta realização, o agora, o instante que recusa a perpetuidade, em contraste com a literatura tradicional; a terceira ocorrência comum é a hipermidiatização da poesia, como a iconografia poética, que descentraliza o uso verbal, pondo-o em trânsito com imagens e outros signos. Na poesia videótica, o caráter efêmero de realização sofre o paradoxo da eternidade do registro videográfico e sua ocorrência, como menciona o autor, se dará pela constância de público leitor - e Fevereiro assegura esta presença pelo número crescente de visualizações, dado que conta com quase cem mil acessos em sua publicação. Sobre estas características peculiares das ocorrências poéticas virtuais, Ramos (2013) percebe tratar-se de uma atualização cultural que acompanha a atualização social:

Como os gêneros textuais, a criação literária também tende a se ajustar às especificidades de permanência e transmissão apresentadas pelos suportes, sejam eles a voz, a parede de uma caverna, o livro ou a tela de computador (RAMOS, 2013, p. 7).

O autor também traz à tona outra característica do processo que é a desterritorialização dos seus agentes, uma vez que tanto autor quanto seus 
leitores têm a possibilidade de estar em qualquer lugar, desde que conectados à rede, para manifestar-se, o que muito contribui para o estatuto de fluidez cultural defendida no início deste artigo.

Eis que a hibridação destas duas reflexões (epistolografia poética e literatura na internet) levou à criação do conceito de e-pístola para caracterizar o corpus deste trabalho, bem como localizar o espaço de criação literária em questão. Esta caracterização (não definição), portanto, serve de síntese à discussão sobre a forma em estudo e pode ser visto como fruto dos aspectos culturais e sociais aventados no artigo.

\section{REFERÊNCIAS}

ANTONIO, J. L. Poesia eletrônica: negociações com os processos digitais. Tese. Doutorado em Comunicação e Cultura - Signo e Significado nas Mídias, curso de Pós-graduação em Letras, Pontifícia Universidade Católica de São Paulo, 2005.

AMÂNCIO, C. M. O conceito de videopoesia e a não obrigatoriedade de presença da linguagem verbal nessas obras. Texto Digital. Florianópolis, v. 10, n. 1, p. 202-220, jan./jul. 2014.

BAGNO, Marcos. Português ou brasileiro? (um convite à pesquisa). São Paulo: Parábola, 2001.

BHABHA, Homi K. O local da cultura. Ed. UFMG, 1998.

CAMPILHO, M. Fevereiro. Canal de vídeos "macmakuu", Youtube, publicado em 11 de março de 2014. Acesso em 27 mar. 2015. Online. Disponivel em: 〈https://www.youtube.com/watch?v=VasLnEWnAxY〉.

CAMPILHO, M. Jóquei. São Paulo: Editora 34, 2015.

CHION, Michel. La musique au cinéma. Fayard, 1995.

CULTURA ÍPSILON. Portugal e Brasil: orgulho e preconceito entre duas literaturas, por LUCAS, I. Publicado em mar. 2015. Acesso em 16 jun. 2015. Online.

Disponivel em: 
<http://www.publico.pt/culturaipsilon/noticia/portugal-e-brasil-orgulhoe-preconceito-entre-duas-literaturas-1690391>.

FAJARDO, C. F. Poesía y posmodernidad - Algunas tendencias y contextos. Revista das Artes. Buenos Aires, n. 26, 2011.

GARCIA, A. A. Da videopoesia à imagem digital. In: BELMIRO, C. A.; MACIEL, F. I. P.; BAPTISTA, M. C.; MARTINS, A. Onde está a literatura? Seus espaços, seus leitores, seus textos, suas leituras. Belo Horizonte: Editora da UFMG, 2014.

KATO, M.; S. DUARTE, M.E.; CYRINO, S. \& BERLINCK, R. "Português brasileiro no fim do século XIX e na virada do milênio". In: Suzana Cardoso, Jacyra Mota e Rosa Virgínia Matto e Silva (orgs.). Quinhentos anos de história linguística no Brasil. Salvador, Empresa Gráfica da Bahia/Funcultura/Governo da Bahia. Pp. 413-438, 2006.

LOURENÇO, E. A nau de Ícaro e Imagem e miragem da lusofonia. São Paulo: Cia das Letras, 2001.

MACHADO, DE ASSIS. Instinto de nacionalidade. Instinto de Nacionalidade $\mathcal{E}$ Outros Ensaios, 1973.

MARGARIDO, Alfredo. A Lusofonia e os Lusófonos: Novos Mitos Portugueses, Lisboa: Edições Universitárias Lusófonas, 2000.

MENDES, P. C. P. Lusofonia: discursos e representações. O cabo dos trabalhos: revista eletrônica dos programas de mestrado e doutoramento do CES / FEUC / FLUC, nº 1, P. 1-27, 2006.

MUNIZ, Túlio de Souza. As impossibilidades da "lusofonia" e as narrativas acerca do "outro e do "eu" entre Brasil e Portugal. Revista Brasileira de História $\mathcal{E}$ Ciências Sociais, v. 1, n. 2, pp. 1-12. Dezembro de 2009.

PERINI, Mário A. Gramática descritiva do português. São Paulo: Ática, 1995.

PRADO, P. F. As cartas portuguesas e a tradição do "amor infeliz" na Literatura portuguesa de voz feminina. Revista Linguas $\mathcal{E}$ Letras. Cascavel, v. 11, n. 21, p. 1-17, 2010. 
. O modelo epistolar das Cartas Portuguesas. Revista Travessias. Cascavel, v. 5, n. 2, p. 627-643, 2011.

RAMOS, T. C. A literatura brasileira na internet: implicações do digital na narrativa. Dissertação. Mestrado em Teoria da Literatura - Curso de Pósgraduação em Letras, Universidade Federal de Pernambuco, 2013.

ROCHA, A. C. A epistolografia em Portugal. Coimbra: Almedina, 1965.

SANTAELLA, Lucia. Matrizes da linguagem e pensamento - sonora, visual, verbal. São Paulo: Iluminuras/FAPESP, 2001.

TARALLO, Fernando. Diagnosticando uma gramática brasileira: o português d'aquém e d'além-mar ao final do século XIX. In ROBERTS, Ian \& M. A. KATO (orgs.) Português Brasileiro: uma viagem diacrônica. Campinas: Ed. da UNICAMP. pp. 69-106, 1993.

. \& Mary A. KATO. Harmonia trans-sistêmica: variação inter e intralinguística. In: Preedição 5. Campinas, Unicamp. 315-353, 1989.

Recebido em: 03/07/2016

Aceito em: 21/07/2016 